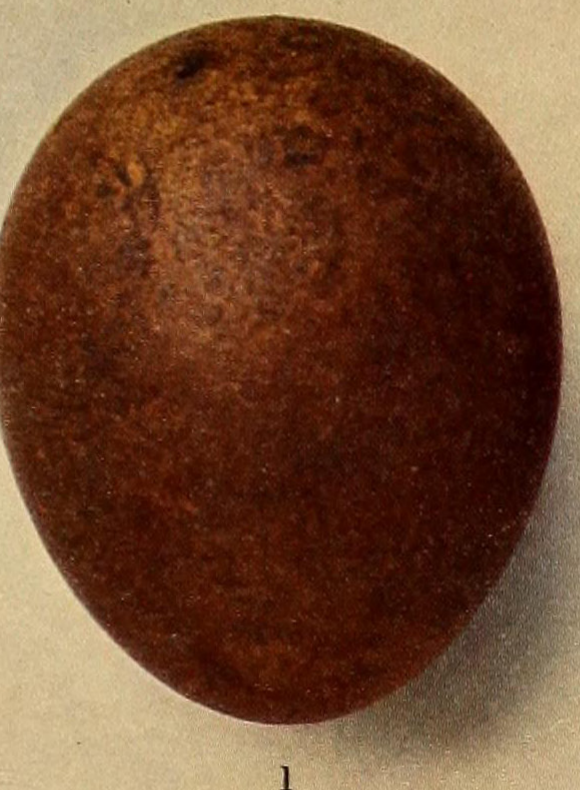

1
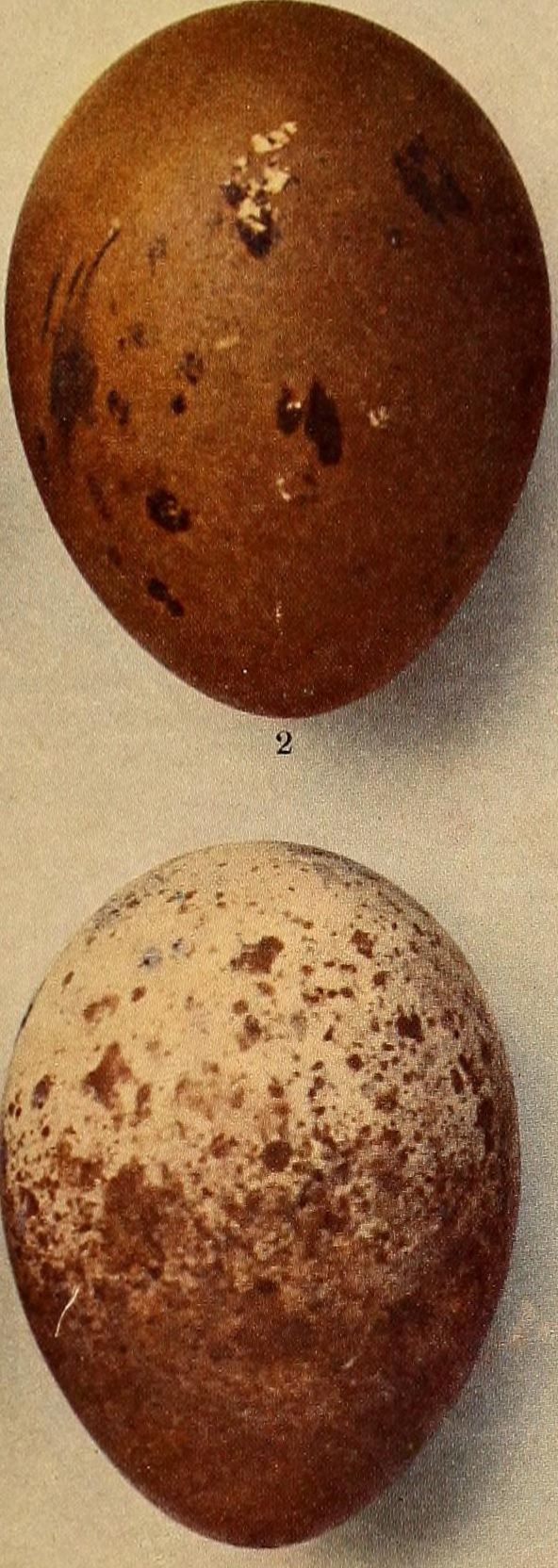

5
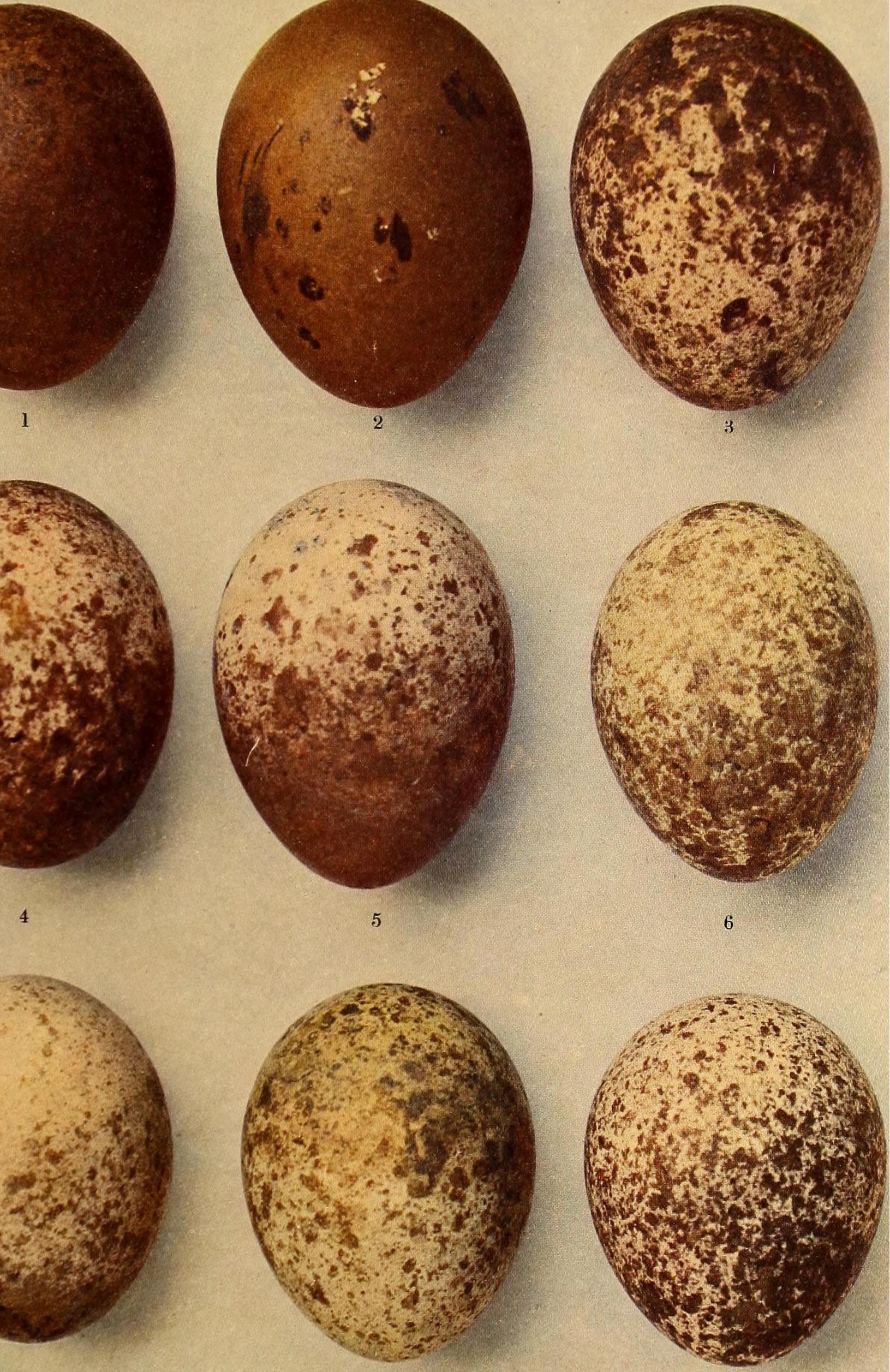


\title{
ESSA TAL \\ GEODIVERSIDADE...
}

\author{
MARIA MÁRCIA MAGELA MACHADO: \\ ÚRSULA RUCHKYS DE AZEVEDO:*
}

RESU MO Este artigo apresenta, de forma sucinta, o conceito de geodiversidade. O termo surgiu a partir de um movimento de conscientização da importância de se proteger os elementos não bióticos da natureza e diz respeito à variedade de estruturas e materiais que constituem o substrato físico natural, o qual suporta a biodiversidade. À medida que estudos sobre o tema foram avançando, surgiram conceitos associados, que explicitam essa nova postura de parte da comunidade geocientífica, entre eles: geossítio, geopatrimônio, geoconservação, geoturismo e geoparque. Embora elementos da geodiversidade guardem parte da memória da evolução do planeta e, portanto, devam ser conservados para usufruto das gerações futuras, as pesquisas ainda são incipientes quando comparadas às de biodiversidade ou de outras categorias de patrimônio.

PALAVRAS-CHAVE Geodiversidade. geoconservação. geopatrimônio.

\section{THIS SO-CALLED GEODIVERSITY ...}

ABSTRACT The essay deals with the concept of geodiversity. The term arose from an awareness of the importance of movement to protect non- biotic elements of nature, in the 1990s, and concerns the variety of structures and materials that make up the natural physical substrate, which supports biodiversity. As studies on the subject were advancing, there were associated concepts that explain this new posture of the geoscientific community, including: geosite, geopatrimônio, geoconservation, geotourism and Geopark. Although geodiversity elements keep some memory of the evolution of the planet and therefore must be preserved for the benefit of future generations, research is still incipient when compared to biodiversity or those linked to other types of heritage.

KEYWORDS Geodiversity. geoconservation. geoheritage.

\footnotetext{
* Professoras Adjuntas do Instituto de Geociências da Universidade Federal de Minas Gerais

E-mail:mmarciamm@ufmg.br

E-mail: tularuchkys@yahoo.com.br

Recebido em 9/12/2015. Aprovado em 30/3/2016.
} 


\section{O que é?}

diversidade natural pode ser entendida sob duas vertentes que se relacionam:
a biodiversidade e a geodiversidade. Da mesma forma que a biodiversidade corresponde à diversidade da natureza viva, a geodiversidade corresponde à variedade de estruturas e materiais que constituem o substrato físico natural, o qual suporta a biodiversidade. Para a Associação Europeia para a Conservação do Patrimônio Geológico (PROGEO) e para a Sociedade Real da Conservação da Natureza do Reino Unido, a geodiversidade consiste na variedade de ambientes geológicos, fenômenos e processos ativos geradores de paisagem (relevo), rochas, minerais, fósseis, solos e outros depósitos superficiais que constituem a base para a vida na Terra (Ruchkys, 2007).

Apesar de ser de uso recente, o termo biodiversidade é hoje um dos mais conhecidos e difundidos no mundo. Foi idealizado, em I985, pelo botânico americano Walter G. Rosen quando organizava o fórum nacional dos Estados Unidos sobre diversidade biológica. O evento foi realizado no ano seguinte com o nome de Fórum Nacional sobre BioDiversidade (Wilson, 1997). A introdução desse neologismo na literatura científica se deu em I988, com a publicação do livro organizado pelo ecólogo Edward O. Wilson, que reúne justamente artigos de especialistas que participaram do Fórum (Franco, 20I3).

O conceito de geodiversidade é da década seguinte. Segundo Brilha (2005), esse termo foi utilizado pela primeira vez na Conferência de Malvern sobre Conservação Geológica e Paisagística realizada, em I993, no Reino Unido. Sua origem está relacionada a um movimento de conscientização da importância de se proteger os elementos não bióticos da natureza. O conhecimento dos elementos abióticos da natureza era, até então, aplicado fundamentalmente à pesquisa e prospecção dos recursos minerais e energéticos, por serem esses estratégicos aos interesses das nações, visto que constituem insumos essenciais a praticamente todos os ramos do setor industrial. Entretanto, principalmente a partir da Conferência das Nações Unidas sobre Meio Ambiente 
e Desenvolvimento, II Cimeira da Terra, conhecida por RIO-92, ganhou força outra aplicação do conhecimento da geodiversidade relacionado às questões ambientais que necessitam de um melhor entendimento dos vários aspectos naturais do planeta, químicos, físicos, biológicos e geológicos e suas interações (Machado \& Ruchkys, 20I0).

A geodiversidade é uma chave essencial para a compreensão do passado da Terra, dos processos atualmente em operação e da sua provável evolução. Nesse sentido, a atribuição de valores para elementos da geodiversidade, sob outras óticas que não a econômica, justificam a necessidade de conservação. Gray (2004) propôs sete categorias principais de valores: intrínsecos ou de existência, culturais (influência sobre folclore, arquitetura, história e religião), estéticos (oportunidade de lazer, contemplação, inspiração para a arte), econômicos (recursos minerais e energéticos), funcionais (sobretudo como substrato para os ecossistemas), científicos e educacionais.

Assim, alguns elementos da geodiversidade podem ter um elevado interesse científico, educativo, cultural e turístico, e, em razão disso, outros conceitos são a eles associados, como geopatrimônio, geossítio, geoconservação, geoturismo e geoparque.

\section{Conceitos associados}

A palavra patrimônio, em inglês heritage, em espanhol herencia, está associada à ideia de herança, aquilo que é transmitido de geração para geração. Nas últimas décadas, a caracterização ou tipificação dos bens considerados patrimônio explicita a incorporação de novos significados ao termo. Segundo Choay (200I), esta requalificação por associação de adjetivos à palavra patrimônio como, por exemplo, genético, natural, cultural, histórico fizeram dela um conceito nômade.

A Convenção para Proteção do Patrimônio Mundial, Cultural e Natural, adotada pela UNESCO em Conferência Geral realizada, em Paris, em novembro de I972, constitui um dos instrumentos mais importantes tanto para conceituação do patrimônio de valor universal quanto para sua proteção e conservação. Essa Convenção da UNESCO trata, em seu Artigo $2^{\circ}$ do patrimônio natural onde estão incluídos elementos da geodiversidade, citando, especificamente, as formações geológicas.

Nos últimos anos, aconteceram avanços nas reflexões sobre a importância da conservação de um conjunto de elementos abióticos da natureza e surgiu, especificamen- 
te, o conceito de geopatrimônio ou patrimônio geológico. Segundo Mansur (2010), o conceito de geopatrimônio adveio de uma nova abordagem do patrimônio natural baseada na evidência da relevância de seus aspectos geológicos. Rivas et al. (200I) definem patrimônio geológico como os recursos naturais não renováveis de valor científico, cultural, educativo e/ou de interesse paisagístico e recreativo, quer sejam formações rochosas, estruturas, geoformas, acumulações sedimentares ocorrências minerais, paleontológicas ou outras que permitam reconhecer, estudar e interpretar a evolução da história geológica da Terra e os processos que a têm modelado.

O geopatrimônio é composto de locais específicos, geossítios, onde ocorrem um ou mais elementos da geodiversidade com valor singular do ponto de vista científico, pedagógico, cultural, turístico entre outros. Um geossítio é, então, um local, geograficamente definido, que constitui um recurso documental de caráter científico e conteúdo importante para o conhecimento e estudo da evolução dos processos geológicos e, por conseguinte, um registro da evolução do planeta.

Muitas paisagens naturais espetaculares e mundialmente famosas são exemplos bem representativos da geodiversidade de nosso planeta e verdadeiros geopatrimônios: o Grande Cânion e os vulcões do Havaí nos EUA, a Calçada dos Gigantes na Irlanda do Norte, as formações geológicas resultantes de fenômenos vulcânicos e de erosão que constituem a estonteante paisagem da Capadócia, as cavernas de kocjan na Eslovênia, os glaciares da Argentina e, especificamente no Brasil, um de nossos mais famosos cartões postais, o Pão de Açúcar no Rio de Janeiro.

Um geopatrimônio é apenas uma pequena parcela da geodiversidade que apresenta características especiais e que, por conseguinte, deve ser conservada. Um marco na mobilização para divulgação e proteção desse patrimônio é a “Declaração Internacional dos Direitos à Memória da Terra" editada ao final do Primeiro Simpósio Internacional sobre a Proteção do Patrimônio Geológico, realizado em I99I, em Digne Les Bains, França. O texto poético ampliou o alcance desse tema em nível mundial, sensibilizando e promovendo discussões no âmbito da comunidade geológica.

A proteção desse tipo específico de patrimônio é comumente denominada de geoconservação e se fundamenta no valor e interesse a ele atribuído A identificação de geossítios prioritários para conservação deve considerar ainda alguns aspectos como a escala de trabalho, o tamanho da área, as características geológicas regionais, entre 


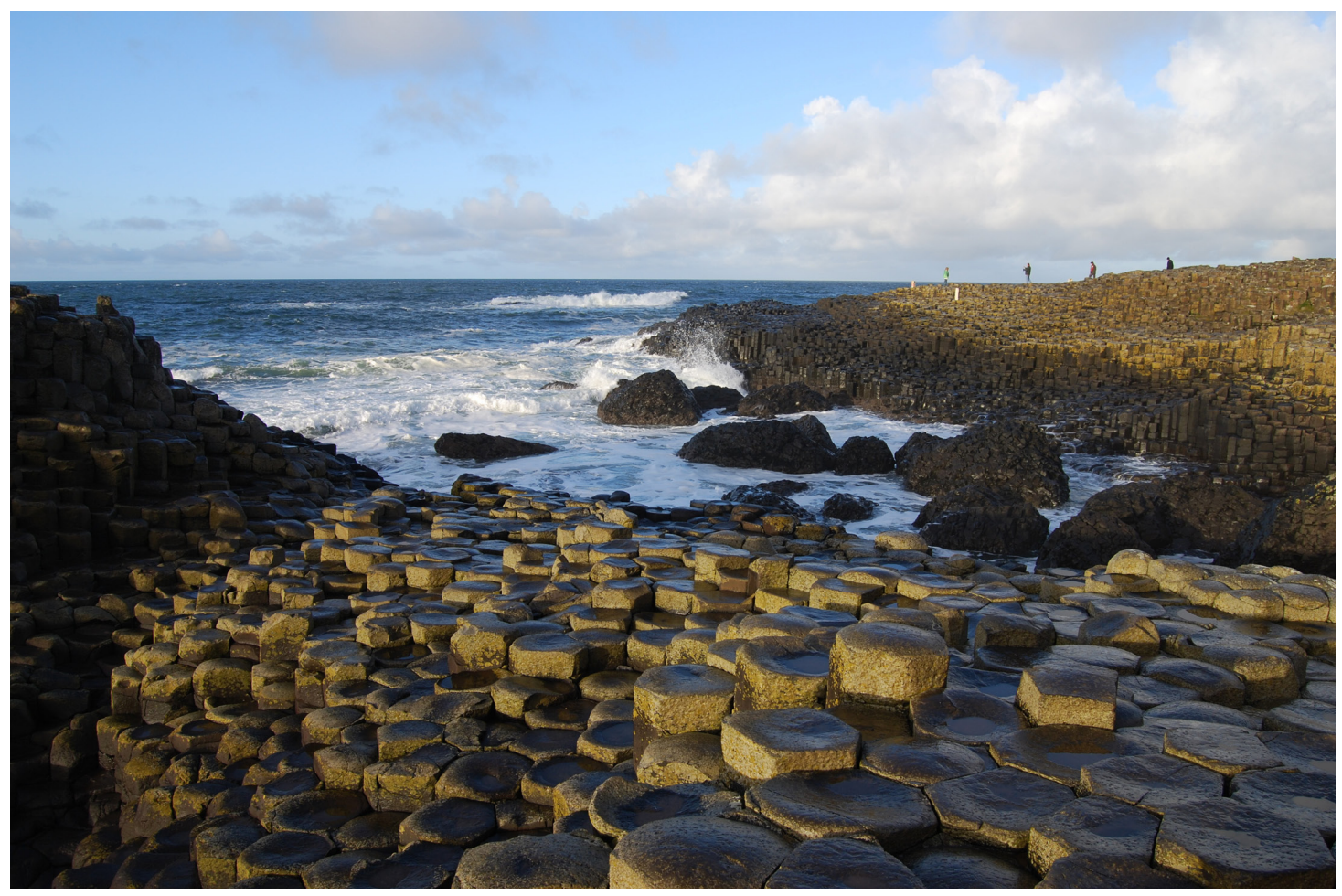

Fig. 1 - Calçada dos Gigantes, Irlanda do Norte - Conjunto de cerca de 40000 colunas prismáticas de basalto resultantes de uma erupção vulcânica ocorrida há cerca de 60 milhões de anos.

Fonte: https://commons.wikimedia.org/w/index.php?curid=9103972)

outros. Sharples (2002) argumenta que a geoconservação não é necessária apenas por ser fundamental à manutenção da biodiversidade, mas por ter a geodiversidade um valor intrínseco independente de estar associada ou não a alguma forma de vida.

Brilha (2005), afirma que "de modo geral, pode-se dizer que a necessidade de conservar um determinado geossítio é igual à soma do seu valor mais as ameaças que ele enfrenta”. São várias as ameaças que pesam sobre a geodiversidade, entre as quais podemos citar como exemplo: a mineração, quando realizada de forma desordenada; a construção de grandes obras de engenharia e a coleta e o comércio de amostras de minerais ou de fósseis raros. Além disso, há um desconhecimento, tanto por parte de legisladores como de gestores, de que os elementos da geodiversidade podem ter um valor patrimonial e que, portanto, merecem ser conservados. 
Ações de geoconservação incluem, geralmente, o uso educativo e turístico dos geossítios, seja de forma pontual, ou do ponto de vista do planejamento territorial e da integração de geossítios com formatação de roteiros temáticos. A ideia desse novo segmento de turismo, que ficou conhecido como geoturismo, é agregar à visitação de áreas naturais conhecimento científico, de forma compreensível e agradável, a fim de possibilitar a valorização e a conservação dos sítios do geopatrimônio.

O inglês Thomas A. Hose introduziu o conceito de geoturismo na literatura científica como a "provisão de serviços e facilidades interpretativas a fim de possibilitar aos turistas a compreensão e aquisição de conhecimentos de um sítio geológico e geomorfológico ao invés da simples apreciação estética” (Hose, I995). Em 2000, o autor fez uma revisão na sua conceituação inicial e propôs que o termo geoturismo fosse usado para a "disponibilização de serviços e meios interpretativos que promovem o valor e os benefícios sociais de lugares com atrativos geológicos e geomorfológicos, assegurando sua conservação, para o uso de estudantes, turistas e outras pessoas com interesses recreativos e de ócio” (HOSE, 2000). A nova proposta, além de manter o foco nos elementos da geodiversidade, apresenta o geoturismo como uma estratégia de desenvolvimento local e de geoconservação. Essas premissas introduzidas estão associadas a outro conceito, o de geoparque.

Um geoparque pode ser entendido como uma porção de um território com limites bem definidos que tem um conjunto de geossítios representativos da história geológica daquela região e, com base no significado desse patrimônio, são desenvolvidas ações educativas e conservacionistas integrando cultura, geologia, educação, economia e conservação.

A proposta de Geoparques, que foi apresentada pela UNESCO à comunidade científica em I999, destaca-se por atender à necessidade específica de reconhecimento e conservação de elementos da geodiversidade da mesma forma como o Programa Reserva da Biosfera se destaca por sua ênfase em patrimônio biológico. A questão central que impulsionou a criação da proposta reside na dificuldade de integrar a proteção e promoção do geopatrimônio (interesse científico) com os processos associados ao desenvolvimento econômico dos territórios e as necessidades das comunidades que o habitam. Até o ano passado, essa proposta não integrava um Programa oficial da UNESCO, mas os geoparques mundiais por ela reconhecidos foram criados sob seus auspícios. A partir de 
I7 de novembro de 20I5, o Programa Geoparques passou a ser reconhecido oficialmente como um novo rótulo da UNESCO, o que expressa o reconhecimento governamental mundial sobre a importância do reconhecimento e gestão do geopatrimônio. A ideia é aliar conservação do patrimônio geológico, educação ambiental e geoturismo em favor da economia local, sem criar qualquer restrição ao desenvolvimento das mais diversas atividades econômicas dentro dos limites do geoparque, inclusive aquelas que têm como matéria-prima recursos minerais. Isso é possível porque o princípio da geoconservação é pontual, apenas dos geossítios, e não da área de forma geral. Segundo o próprio conceito, o geoparque é dinâmico. Continuamente é possível propor alterações no que tange aos geossítios, tanto inclusões como exclusões.

Um geoparque não é mais uma categoria de área protegida (parque nacional, parque estadual, estação ecológica, etc.), mas outro modo de entender a conservação e o uso dos recursos da geodiversidade. Atualmente, a Rede Global de Geoparques assistida pela UNESCO é constituída por 120 geoparques, distribuídos em 33 países, com grande concentração em países europeus e na China (Fig. 2).

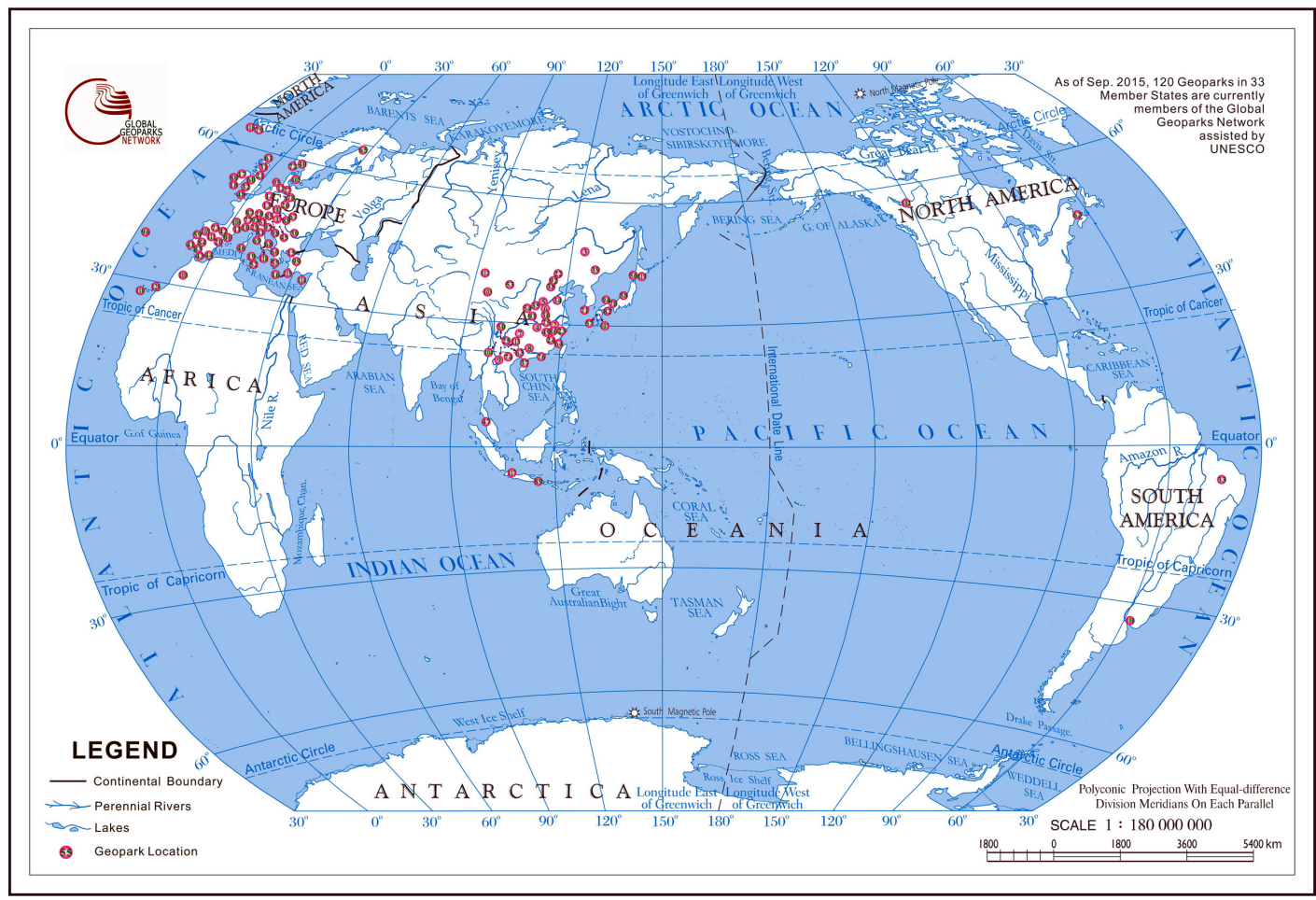

Fig. 2 - Mapa de localização dos geoparques que integram a Rede Gobal da UNESCO

http://www.globalgeopark.org/homepageaux/tupai/6513.htm 

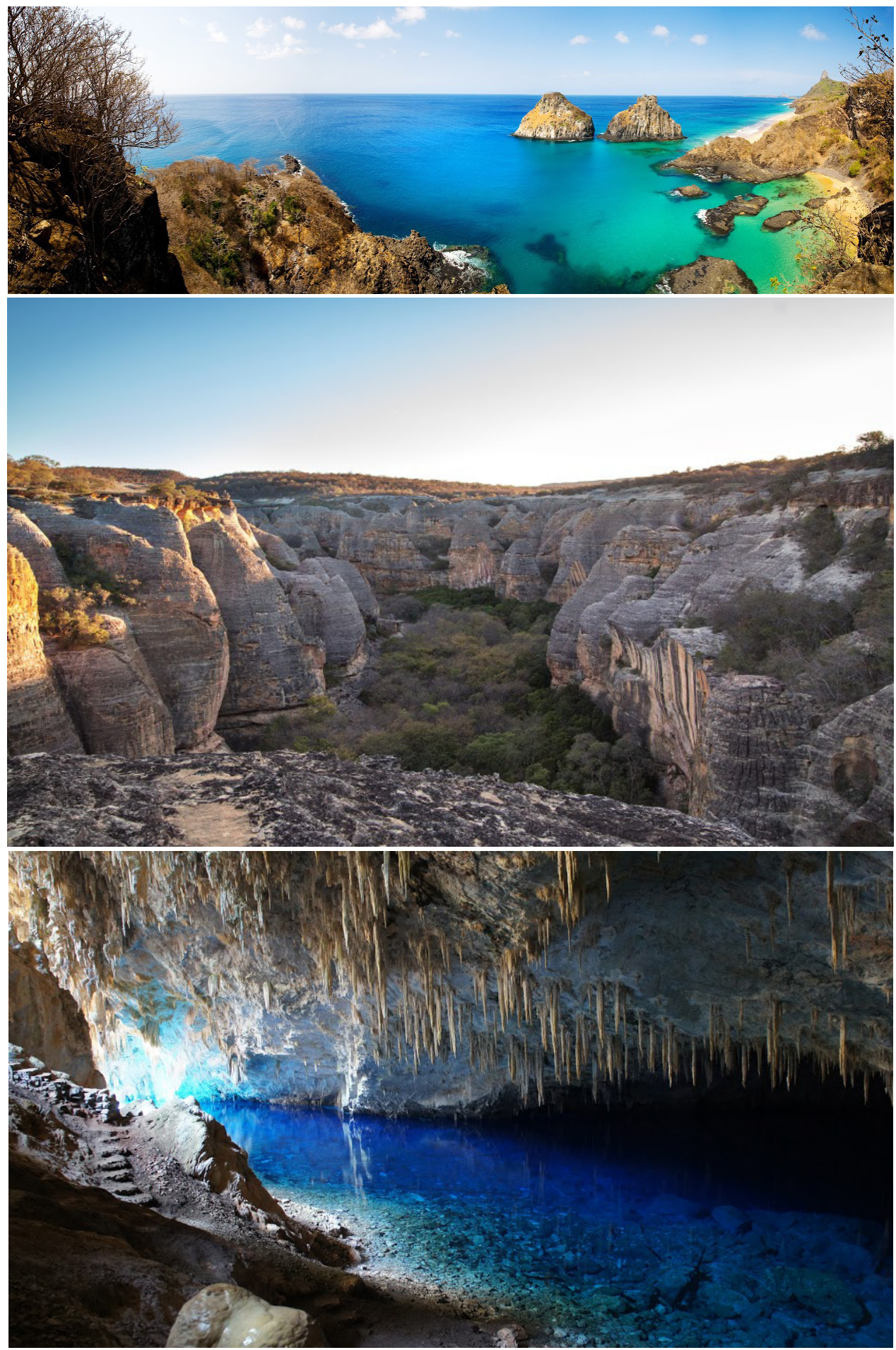

Fig. 3 - (a) Vista Panorâmica da Baía dos Porcos - Fernando de Noronha, PE (Foto: Eduardo Muruci, from Wikimedia Commons); (b) Vista do Parque Nacional da Serra da Capivara, PI (Foto: Artur Warchavchik, from Wikimedia Commons); (c) Gruta Lago Azul - Bonito, MS (Foto: Sidney Michaluate, from Wikimedia Commons) 
No Brasil, o conceito de geoparques começou a ser incorporado em 2006 com a criação do Geoparque Araripe, no estado do Ceará. No mesmo ano, o Serviço Geológico do Brasil lançou o Projeto Geoparques a fim de induzir a criação de geoparques no país. Em 20I2, foi publicado o livro Geoparques do Brasil: propostas, com a descrição de I7 áreas com aptidão para criação de geoparques nacionais, entre elas Fernando de Noronha (PE), Serra da Capivara (PI), Bodoquena - Pantanal (MS) (Fig. 3).

Em 2007, foi proposta a criação de um geoparque nos modelos da UNESCO, na região do Quadrilátero Ferrífero em Minas Gerais. A área tem geologia complexa com afloramentos privilegiados de rochas que são testemunhos-chave para o entendimento da evolução geológica do planeta, como os meta-arenitos da Serra do Andaime (Fig. 4), interpretados como uma associação litorânea originados em ambiente marinho raso no Arqueano, sendo, portanto, o registro de uma das primeiras praias do Brasil (Machado \& Ruchkys, 2013). Tem também longa história de exploração mineral que contribuiu para formação da identidade cultural e histórica do estado. É um importante do patrimônio natural do Brasil com enorme biodiversidade e belas paisagens, conforme salientado por Ruchkys (2007) e Machado (2009).

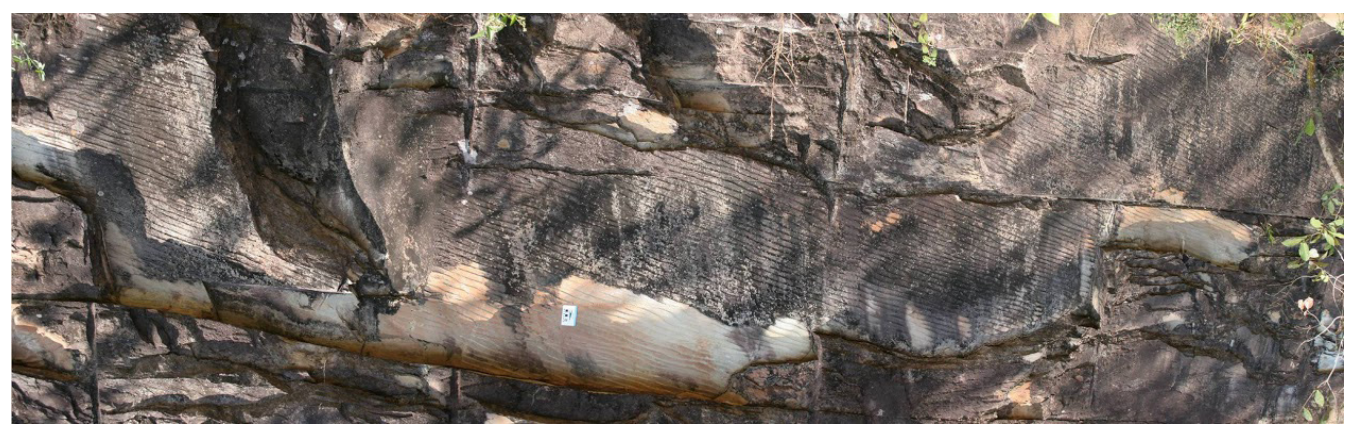

Fig. 4 - Marcas de onda nos meta-arenitos da Serra do Andaime. (Foto: Dionisio Tadeu de Azevedo)

Nos últimos anos, vêm sendo desenvolvidas muitas pesquisas que envolvem o trinômio geodiversidade, geoconservação e geoturismo na região, além de iniciativas para difusão da geologia e promoção do geopatrimônio, entre elas promoção de oficinas, treinamentos de agentes ambientais, palestras e implantação de paineis interpretativos em geossítios (Fig.5). 


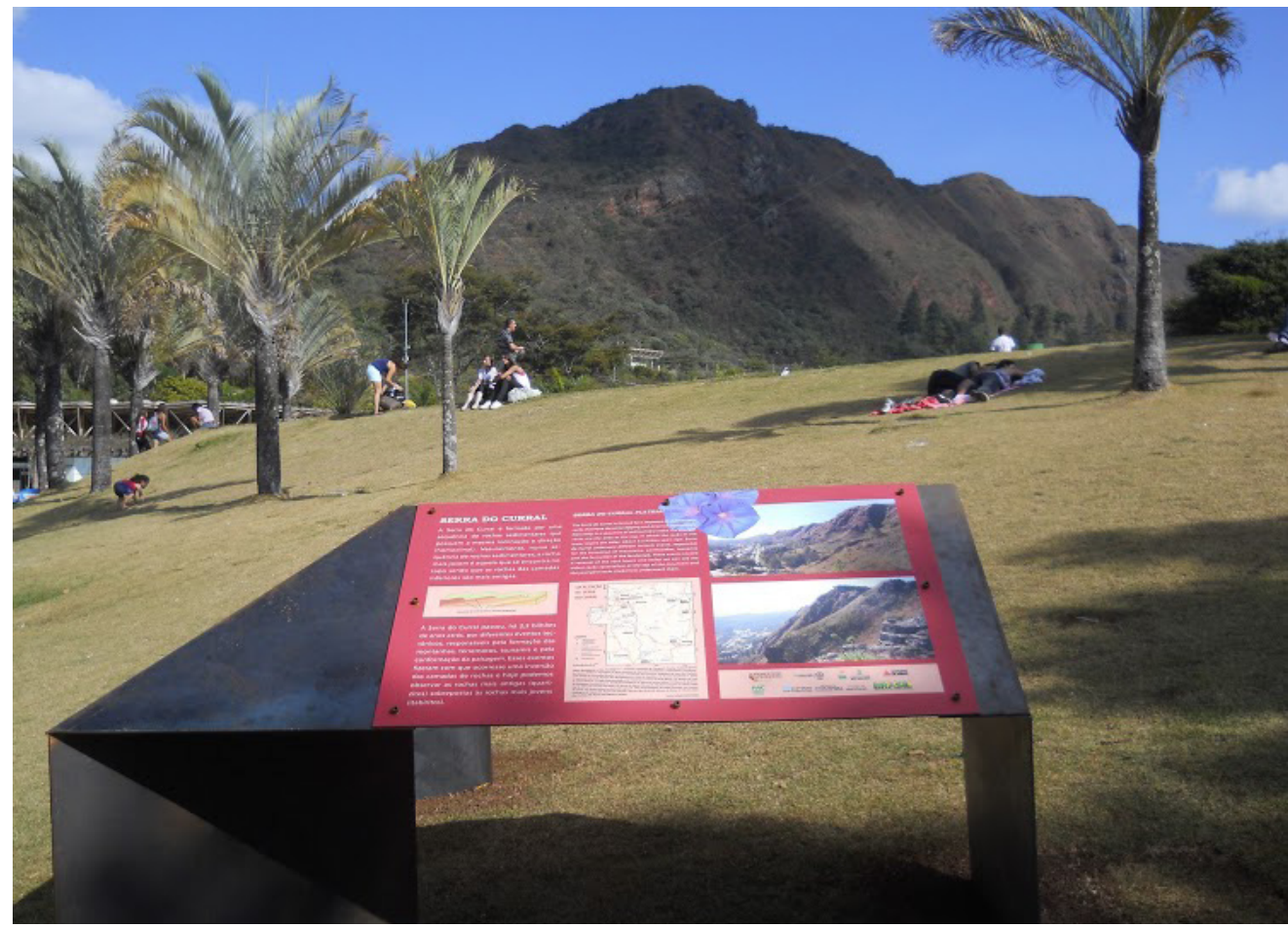

Fig. 5 - Painel interpretativo da Serra do Curral - Parque das Mangabeiras, Belo Horizonte- MG (Foto: Maria Márcia M. Machado)

\section{Considerações finais}

Os estudos da geodiversidade são importantes e explicitam uma visão mais holística da natureza. No Brasil, pesquisas envolvendo esse tema e seus conceitos correlatos: geoconservação, geopatrimônio e geoturismo, estão em franco desenvolvimento. Nos últimos anos, programas de pós-graduação nas mais diversas áreas do conhecimento têm contemplado a geodiversidade brasileira. No entanto, as pesquisas ainda são incipientes quando comparadas às de biodiversidade ou àquelas ligadas a outras categorias de patrimônio.

O país se caracteriza por uma rica geodiversidade com geopatrimônio associado que precisa ser estudado, compreendido e valorizado. Esses elementos guardam parte da memória da evolução do planeta e devem ser conservados para usufruto das futuras gerações. Espera-se que esse breve relato possa contribuir com a difusão desses conceitos e de sua importância. 


\section{Referências}

BRILHA, J. B. Património geológico e geoconservação: a conservação da natureza na sua vertente geológica. Viseu: Palimage Editores, 2005.

CHOAY, F. A. Alegoria do Patrimônio. São Paulo: UNESP, 200 I.

FRANCO, J. L. de A. O conceito de biodiversidade e a história da biologia da conservação: da preservação da wilderness à conservação da biodiversidade. História, Franca, v. 32, n. 2, p. 2I48, Dec. 20I3. Disponível em <http://www.scielo.br/scielo.php?script=sci_arttext\&pid=SoIoI$90742013000200003 \& \operatorname{lng}=e n \& n r m=i s 0>$. Acesso em: I7 Jan. 2016.

GRAY, M. Geodiversity: valuing and conserving abiotic nature. Chichester, UK: John Wiley \& Sons (Ed.), 2004 .

HOSE, T. A. Selling the Story of Britain's Stone, Environmental Interpretation, IO(2): I6-I7. I995.

HOSE, T. A. European "Geotourism" - geological interpretation and geoconservation promotion for tourists. In: D. Barettino, W.A.P. Wimbledon \& E. Gallego (eds.). Geological Heritage: its conservation and management. Madrid, 127-146.

MANSUR, K. L. Ordenamento Territorial e Geoconservação: Análise das Normas Legais Aplicáveis no Brasil e um Caso de Estudo no Estado do Rio de Janeiro. Geociências (São Paulo. Online), v. 29, p. 237-349. 2010

MACHADO, M.M.M. 2009. Construindo a imagem geológica do Quadrilátero Ferrífero: conceitos e representações. Tese de Doutorado. Instituto de Geociências, Universidade Federal de Minas Gerais, Belo Horizonte. 238p.

MACHADO, M.M.M., RUCHKYS, U.A. Valorizar e divulgar a geodiversidade: estratégias do Centro de Referência em Patrimônio Geológico CRPG - MHNJB/UFMG. Geonomos I8(2): 53-56. 2010 .

RIVAS, F.V., RIVERA, F.M., GUADALUPE, G. Situación Ambiental del Patrimônio Geológico em El Perú. Revista Del Instituto de Investigación, v. 4, n. 8, p. 30-36, 200I. Disponível em: http://www.scielo.org.pe/pdf/iigeo/v4n8/a04v4n8.pdf. Acesso em: 7 dez. 2015.

RUCHKYS, U.A. 2007. Patrimônio geológico e geoconservação no Quadrilátero Ferrífero, Minas Gerais: potencial para a criação de um geoparque da UNESCO. Tese de Doutorado, Instituto de Geociências, Universidade Federal de Minas Gerais, Belo Horizonte. 2IIp.

RUCHKYS, U.A., MACHADO, M.M.M. Patrimônio geológico e mineiro do Quadrilátero Ferrífero, Minas Gerais - Caracterização e iniciativas de uso para educação e geoturismo. Boletim Paranaense de Geociências 70: 120-136. 2013.

SHARPLES, C. Concepts and principles of geoconservation. Published electronically on the Tasmanin Parks \& Wildlife Service web site. 3. ed. set, 2002

WILSON, Edward O. (Org.). Biodiversidade. Rio de Janeiro: Nova Fronteira, I997. 